University of Nebraska - Lincoln

DigitalCommons@University of Nebraska - Lincoln

Simultaneous cognate epitope recognition by bovine CD4 and

CD8 T cells is essential for primary expansion of antigen-specific

cytotoxic T-cells following ex vivo stimulation with a candidate Mycobacterium avium subsp. paratuberculosis peptide vaccine

Gaber S. Abdellrazeq

Lindsay M. Fry

Mahmoud M. Elnaggar

J. P. Bannantine

David A. Schneider

See next page for additional authors

Follow this and additional works at: https://digitalcommons.unl.edu/usdaarsfacpub

Part of the Agriculture Commons

This Article is brought to you for free and open access by the U.S. Department of Agriculture: Agricultural Research Service, Lincoln, Nebraska at DigitalCommons@University of Nebraska - Lincoln. It has been accepted for inclusion in Publications from USDA-ARS / UNL Faculty by an authorized administrator of DigitalCommons@University of Nebraska - Lincoln. 


\section{Authors}

Gaber S. Abdellrazeq, Lindsay M. Fry, Mahmoud M. Elnaggar, J. P. Bannantine, David A. Schneider, William M. Chamberlin, Asmaa H.A. Mahmoud, Kun-Taek Park, Victoria Hulubei, and William C. Davis 


\title{
Simultaneous cognate epitope recognition by bovine CD4 and CD8 T cells is essential for primary expansion of antigen-specific cytotoxic T-cells following ex vivo stimulation with a candidate Mycobacterium avium subsp. paratuberculosis peptide vaccine
}

\author{
Gaber S. Abdellrazeq ${ }^{\mathrm{a}, \mathrm{b}}$, Lindsay M. Fry ${ }^{\mathrm{c}}$, Mahmoud M. Elnaggar ${ }^{\mathrm{a}, \mathrm{b}}$, John P. Bannantine ${ }^{\mathrm{d}}$, \\ David A. Schneider ${ }^{\mathrm{c}}$, William M. Chamberlin ${ }^{1}$, Asmaa H.A. Mahmoud ${ }^{\mathrm{a}, \mathrm{e}}$, Kun-Taek Park ${ }^{\mathrm{f}}$, Victoria Hulubei ${ }^{\mathrm{a}}$, \\ William C. Davis ${ }^{\mathrm{a}, *}$ \\ a Department of Veterinary Microbiology and Pathology, Washington State University, Pullman WA, USA \\ ${ }^{\mathrm{b}}$ Department of Microbiology, Faculty of Veterinary Medicine, Alexandria University, Egypt \\ ${ }^{\mathrm{C}}$ USDA, ARS, Animal Disease Research Unit, Pullman, WA, USA \\ ${ }^{\mathrm{d}}$ USDA, ARS, National Animal Disease Center, Ames, IA, USA \\ ${ }^{\mathrm{e}}$ Veterinary Quarantine of Alexandria, General Organization for Veterinary Services, Ministry of Agriculture and Land Reclamation, Egypt \\ ${ }^{\mathrm{f}}$ Department of Biotechnology, Inje University, Injero 197, Kimhae-si, Gyeongsangnam-do, Republic of Korea
}

\section{A R T I C L E I N F O}

\section{Article history:}

Received 10 June 2019

Received in revised form 28 October 2019

Accepted 22 December 2019

Available online 3 January 2020

\section{Keywords:}

Bovine

Dendritic cells

T cells

Paratuberculosis

Mycobacterium avium subsp.

paratuberculosis

Cognate epitope recognition

Cytotoxicity

Vaccination

Propidium monoazide

\begin{abstract}
A B S T R A C T
Studies in cattle show CD8 cytotoxic T cells (CTL), with the ability to kill intracellular bacteria, develop following stimulation of monocyte-depleted peripheral blood mononuclear cells (mdPBMC) with antigen presenting cells (APC, i.e. conventional dendritic cells $[\mathrm{CDC}]$ and monocyte-derived $\mathrm{DC}[\mathrm{MoDC}]$ ) pulsed with MMP, a membrane protein from Mycobacterium avium subsp. paratuberculosis (Map) encoded by MAP2121c. CTL activity was diminished if CD4 T cells were depleted from mdPBMC before antigen (Ag) presentation by APC, suggesting simultaneous cognate recognition of MMP epitopes presented by MHC I and MHC II molecules to CD4 and CD8 T cells is essential for development of CTL activity. To explore this possibility, studies were conducted with mdPBMC cultures in the presence of monoclonal antibodies (mAbs) specific for MHC class I and MHC class II molecules. The CTL response of mdPBMC to MMP-pulsed APC was completely blocked in the presence of mAbs to both MHC I and II molecules and also blocked in the presence of mAbs to either MHC I or MHC II alone. The results demonstrate simultaneous cognate recognition of Ag by CD4 and CD8 $\mathrm{T}$ cells is essential for delivery of CD4 T cell help to CD8 T cells to elicit development of CTL.
\end{abstract}

(c) 2019 Elsevier Ltd. All rights reserved.

\section{Introduction}

Mycobacterium avium subspecies paratuberculosis (Map) is a higher-order bacterial pathogen with a broad host range that includes livestock and humans [1,2]. Similar to M. tuberculosis and $M$. bovis, initial infection leads to development of a persistent

Abbreviations: mdPBMC, monocyte-depleted peripheral blood mononuclear cells; cDC, conventional dendritic cells; MoDC, monocyte-derived DC; MoMФ, monocyte-derived macrophages; Map, Mycobacterium avium subsp. paratuberculosis; WT, wild type; MMP, 35 kDa membrane peptide; PMA, Propidium monoazide; qPCR, quantitative PCR; $C_{\mathrm{T}}$, cycle threshold.

* Corresponding author.

E-mail address: davisw@wsu.edu (W.C. Davis).

1 Retired. infection under immune control. In some cases, immune control may become compromised, leading to granulomatous ileitis, malabsorption, wasting, and death [3].

Paratuberculosis (Ptb), also referred to as Johne's disease (JD) in ruminants, is a significant cause of livestock morbidity and mortality worldwide. The increased incidence of Map infection in ruminants has been accompanied by an increased prevalence of Map infection in humans. Some infected individuals have developed granulomatous ileitis similar to that observed in JD-infected ruminants. Interestingly, the lesions and the resultant intestinal illness are often observed in patients with Crohn's disease (CD) [2,4,5], and Map has been cultured from numerous patients with $\mathrm{CD}$. Such observations have increased interest in developing methods to limit Map infection in livestock, thereby reducing the risk for human exposure. 
With this objective in mind, we developed a candidate peptidebased vaccine for Map that elicits development of CD8 cytotoxic T cells capable of killing intracellular bacteria [6,7]. Following inoculation with wild type (WT) Map or Map deletion mutants (Map/ $\Delta$ relA or Map/spknG $[8,9])$, calves develop both CD4 and CD8 Tcell proliferative responses to Map soluble antigens and Johnin (purified protein derivative, PPD made from Map), both before and after subsequent challenge with Map [10]. Of interest, only the Map/ $\Delta$ relA mutant was unable to establish a persistent infection. In addition, calves inoculated with $M a p / \Delta$ relA exhibited reduced colonization by WT Map on subsequent challenge. These data indicated a difference in the immune response of calves to $M a p / \Delta r e l A$ as compared to that elicited by WT Map [10].

The immune response of a steer inoculated with Map/ $\Delta r e l A$ was evaluated in an attempt to understand why this mutant could not establish a persistent infection. PBMC from the steer were pulsed with live Map/ $\Delta$ relA to examine the recall response [11]. Initial studies showed stimulation of the steer's PBMC with Map/ $\Delta$ relA elicited a proliferative CD4 and CD8 T cell recall response. Analysis of effector activity revealed that the responding CD8 T cells were cytotoxic, killing intracellular bacteria [6]. Minimal induction of cytotoxic activity was detected in the responding CD4 T cell population. Further analysis of the recall immune response to Map/ $\Delta$ relA revealed the target of the response was a $35 \mathrm{kDa}$ membrane peptide, MMP, encoded by MAP2121c [11,12]. An identical CTL recall response was elicited when PBMC were pulsed with Map/DrelA or MMP [6]. The recall responses to Map/ $\Delta$ relA and MMP were blocked in the presence of monoclonal antibodies (mAbs) specific for MHC class I and II molecules, verifying that the CD4 and CD8 T-cell recall responses were MHC restricted. Although in retrospect, studies should have included examination of the effect of antibodies to MHC I alone and MHC II alone, they were not included.

Further investigation using blood from Map unexposed steers revealed the same CTL response could be elicited entirely ex vivo by using two rounds of stimulation of monocyte depleted PBMC (mdPBMC) with APC pulsed with MMP [6]. The proliferative and CTL responses were reduced if either CD4 or CD8 T cells were depleted from mdPBMC before culture with APC pulsed with MMP. This finding suggested CD4 and CD8 T cells had to recognize their respective antigenic epitopes, presented by APC in context of MHC I and MHCII molecules, at the same time for development of CTL. The present study was conducted to explore this possibility in greater detail. As reported, the data provide evidence showing MMP is taken up by APC ( $C D C$ and MoDC) via the exogenous route and processed for Ag presentation by MHC class I and MHC class II molecules. The proliferative and CTL responses were blocked in the presence of antibodies to both MHC I or MHC II as observed in studies of the recall response [6]. The responses were also blocked in the presence of antibody to MHC I alone and also to MHC II alone. This finding provides evidence that CD4 and CD8 T cells must recognize their respective antigens at the same time for development of CTL. Of importance to investigations on development of vaccines, the results answer a longstanding question. How and when is CD4 T cell help delivered to CD8 T cells to elicit development of CD8 cytotoxic T cells?

\section{Material and methods}

\subsection{Animals}

Three Holstein steers were obtained from the Map-free Washington State University (WSU) dairy herd in 2017. The steers were kept in an open feed lot and used as a source of blood to conduct the ex vivo studies on the immune response to MMP. Steers were maintained by the WSU animal care staff, and all protocols were approved by the WSU Institutional Animal Care and Use Committee (ASAFs 3360 and 04883).

\subsection{Preparation of MMP and Map $K 10$}

The full length MMP used for antigen presentation by antigen presenting cells (APC) is encoded by MAP2121c in the K-10 genome $[12,13]$. It was expressed in ClearColi as a maltose-binding protein fusion for purification [14]. Cultures of Map K10 were prepared from single colonies and used to inoculate Middlebrook 7H9 broth flasks (Difco, BD biosciences, USA) supplemented with $6.7 \%$ paraJEM GS (Trek Diagnostic Systems, OH), $2 \mu \mathrm{g} / \mathrm{mL}$ mycobactin J (Allied Monitor, MO, USA), and 0.05\% Tween 80 (Sigma-Aldrich Corp.) $[10,15]$. The cultures were expanded on a shaking stand at $37{ }^{\circ} \mathrm{C}$. When the broth cultures reached an OD600 of 0.6 to 0.8 , master stocks were prepared in $1.5 \mathrm{~mL}$ micro-centrifuge screwcap tubes for immediate use in each experiment. To ensure a single-cell suspension, bacterial stocks were disaggregated by passages through a 26-gauge needle three times, and bacterial numbers were estimated based on the final OD600 values [15].

\subsection{Blood processing for cell separation and culture}

The flow diagram in Fig. 1 illustrates the protocols used to conduct studies with cells obtained from the three Map-negative Holstein steers. As illustrated in Fig. 1, peripheral blood mononuclear cells (PBMC) were prepared by density gradient centrifugation using Ficoll- Hypaque (0.077). One portion of the PBMC was used to generate MoМ $\Phi$ for use in the viability assay as described below. The second PBMC portion was labelled with magnetic microbeads coated with a cross-reactive anti-human CD14 mAb to isolate monocytes per the manufacturer's instructions (Miltenyi Biotec) [16]. The average purity of isolated $\mathrm{CD} 14^{+}$cells was greater than $98 \%$, as determined by FC analysis using an anti-bovine CD14 mAb, CAM36A $[17,18]$. Monocytes $\left(2 \times 10^{6}\right)$ were added to wells of six well culture plates and cultured in $3 \mathrm{~mL}$ of complete culture medium (cRPMI) [RPMI-1640 medium with GlutaMAX ${ }^{\mathrm{TM}}$ (Life Technologies, CA) supplemented with $10 \%$ calf bovine serum (CBS), $1 \mathrm{mM} \beta-$ mercaptoethanol, 100 units $/ \mathrm{mL}$ of penicillin $\mathrm{G}$, and $100 \mu \mathrm{g} / \mathrm{mL}$ of streptomycin sulfate] in the presence of a DC growth cocktail containing bovine GM-CSF and IL-4 (Kingfisher Biotech, MN). On the third day, $1.4 \mathrm{~mL}$ of the medium was replaced with $1.8 \mathrm{~mL}$ of fresh medium containing the cocktail. The cultures were incubated for an additional three days to obtain MoDC.

The mdPBMC were initially incubated for $30 \mathrm{~min}$ at $37{ }^{\circ} \mathrm{C}, 5 \%$ $\mathrm{CO} 2$ with the following combinations of the primary mAbs with no azide $\left(1 \mu \mathrm{g}\right.$ each $/ 10^{6}$ cells): Anti-CD8 and anti- $\gamma \delta$ T cells; Anti-CD 4 and anti- $\gamma \delta$ T cells; and anti- $\gamma \delta$ T cells. After incubation, cells were washed three times with warm RPMI to remove unbound antibodies.

The three sets of primary mAb-treated mdPBMC were then incubated for $15 \mathrm{~min}$ at $4{ }^{\circ} \mathrm{C}$ with anti-mouse IgG2a $+\mathrm{b}$ microbeads per the manufacturer's instructions (Miltenyi Biotec). After incubation, the cells were washed two times with cold MACS buffer (a solution containing phosphate- buffered saline (PBS), pH 7.2, 0.5\% bovine serum albumin (BSA), and $2 \mathrm{mM}$ EDTA) to remove the unbound microbeads, and then re-suspended in the same buffer. For magnetic separation, LS columns were placed in the magnetic field of a MACS Separator and rinsed with $3 \mathrm{~mL}$ of MACS buffer, and cell suspensions were loaded onto the wet columns. Flowthrough containing the following three unlabeled cell fractions of mdPBMC were collected (negative selection): CD4 T cells, CD8 T cells and CD4/CD8 T cells. Unseparated mdPBMC were also maintained for use as positive and negative control wells.

The three mdPBMC fractions and unseparated mdPBMC were subjected to two rounds of antigenic stimulation using MMP. To 


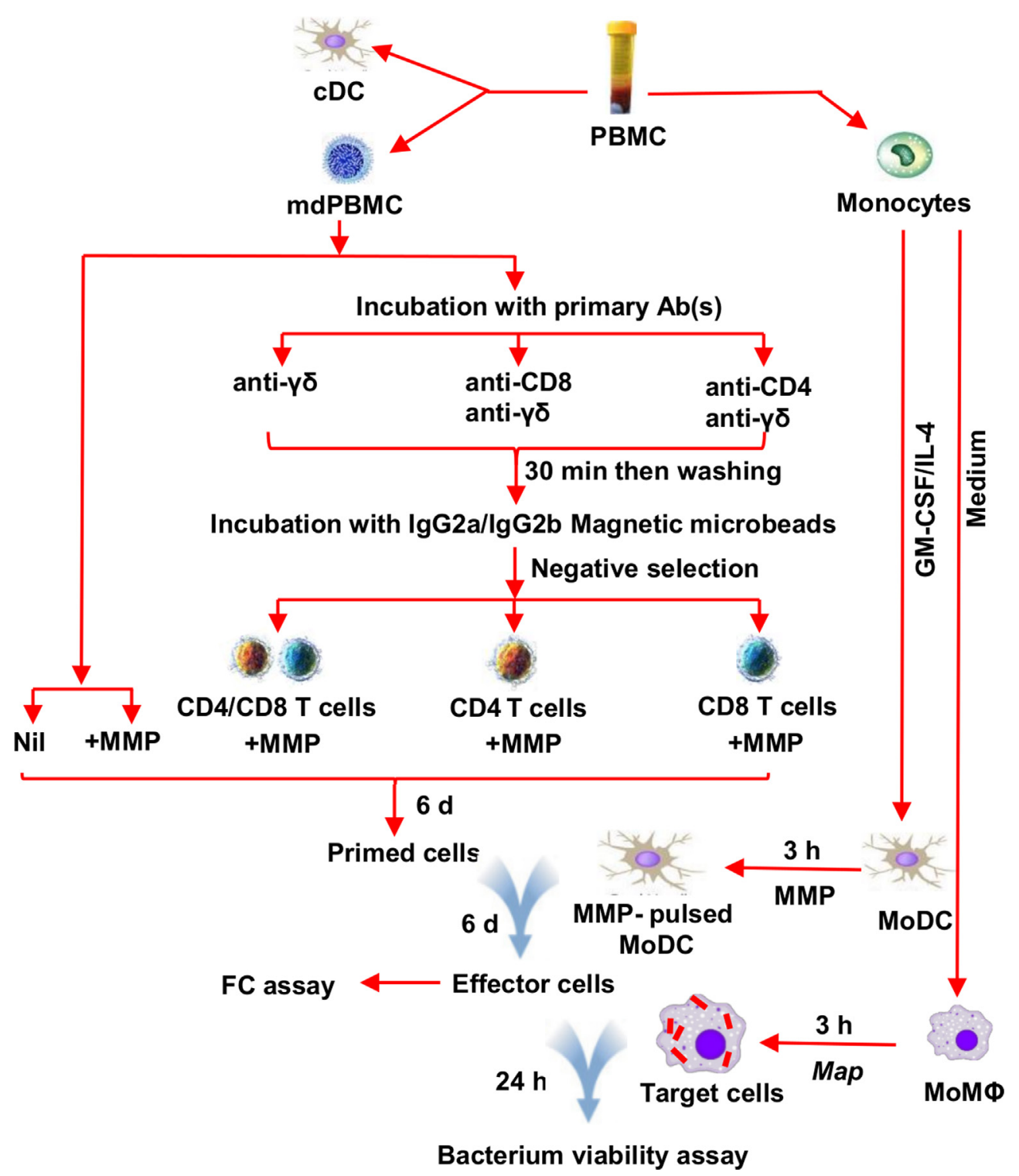

Fig. 1. Flow diagram illustrating preparation of mdPBMC for analysis of the immune response to MMP ex vivo. See methods for detail.

conduct the first round of stimulation, cells were distributed in the 6 -well culture plate in duplicate $\left(2 \times 10^{6} / \mathrm{mL}\right.$ in $5 \mathrm{~mL}$ of cRPMI). MMP $(5 \mu \mathrm{g} / \mathrm{mL})$ was added to each well and incubated for 6 days at $37{ }^{\circ} \mathrm{C}, 5 \% \mathrm{CO} 2$ to allow MMP processing and presentation by cDC present in the mdPBMC. To conduct the second round of stimulation after 6 days of culture, MMP $(5 \mu \mathrm{g} / \mathrm{mL})$ was added to the cultures of MoDC and incubated for $3 \mathrm{~h}$ at $37{ }^{\circ} \mathrm{C}, 5 \% \mathrm{CO}$. The adherent MoDC were then carefully washed 3 times with warm RPMI to remove the cell-free MMP. The primed cells were collected, washed twice with warm RPMI, and added to their respective autologous MoDC pulsed with MMP $\left(2 \times 10^{6} / \mathrm{mL}\right.$ in $5 \mathrm{~mL}$ of cRPMI). After six additional days of culture, the cells were collected and used in FC and the Map viability assay as described below. A portion of the unseparated mAPBMC was maintained as a negative control with no antigen stimulation during the two weeks of cell culture.

\subsection{Viability assay}

Control and antigen-stimulated mdPBMC and CD4 T-cell, CD8 T-cell, and CD4/CD8 T-cell fractions were used as effector CTLs in the viability assay.

\subsubsection{Generation of MoM $\Phi$ for use as target cells}

As mentioned above, one portion of fresh PBMC was resuspended in cRPMI transferred into $150 \mathrm{~mm}$ tissue culture plates and incubated overnight. The majority of the non-adherent cells were then removed the following day. The adherent cells were cultured in fresh medium for six days then brought into suspension by incubation on ice in the presence of EDTA in PBS (4 mL EDTA [ $250 \mathrm{mM}$ stock in H2O], $5 \mathrm{~mL}$ CBS, $91 \mathrm{~mL}$ PBS). The MoMФ were distributed into six well culture plates $\left(2 \times 10^{6}\right.$ cells/ well) and cultured for an additional six days, and then used as target cells in the viability assay.

\subsubsection{Infection of target cells with Map K10}

MoMФ were infected with Map K10 at a multiplicity of infection (MOI) of 10:1 ( $2 \times 10^{7}$ Map to $\sim 2 \times 10^{6} \mathrm{MoM} \Phi /$ well $)$ in antibioticfree cRPMI. Culture plates were centrifuged at $700 \mathrm{~g}$ for five minutes, then incubated at $37{ }^{\circ} \mathrm{C}, 5 \% \mathrm{CO}_{2}$ for $3 \mathrm{~h}$. Extracellular bacteria were removed by washing five times with warm, antibiotic-free RPMI using gentle suction to avoid detaching adherent MoМФ. Two wells from each of the respective sets of 6 wells, containing 
Map infected MoMФ, were used as controls, without addition of primed or unprimed preparations of mdPBMC.

\subsubsection{Incubation of effector $T$ cells with infected target cells}

Stimulated and control mdPBMC and T-cell fractions were collected and added to the preparations of infected MoМФ. Cocultures were incubated for $24 \mathrm{~h}$ at $37{ }^{\circ} \mathrm{C}, 5 \% \mathrm{CO}_{2}$. Non-adherent cells were collected, then adherent cells were detached and collected as described above. Finally, collected adherent and nonadherent cells were recombined for analysis of Map viability.

\subsubsection{Cell lysis}

Following collection, cells were lysed by adding $2 \mathrm{~mL}$ of $0.01 \%$ saponin in $\mathrm{H}_{2} \mathrm{O}$ and incubated at $37^{\circ} \mathrm{C}$ for $15 \mathrm{~min}$. The cell lysates were centrifuged for $30 \mathrm{~min}$ at $4500 \mathrm{rpm}$ to pellet the bacteria. The supernatants were discarded and the pellets re-suspended in $1 \mathrm{~mL}$ $\mathrm{H}_{2} \mathrm{O}$ and transferred into micro-centrifuge tubes, then centrifuged at $14,000 \mathrm{rpm}$ for $10 \mathrm{~min}$. The supernatants were discarded, and the pellets re-suspended in $400 \mu \mathrm{g}$ of $\mathrm{H}_{2} \mathrm{O}$ in $1.5 \mathrm{~mL}$ translucent Eppendorf tubes and stored at $-20^{\circ} \mathrm{C}$ until used.

A set of controls was prepared from known mixtures of live and dead Map K10. This set of controls covered the dynamic range for detection of live vs dead Map obtained from infected MoM $\Phi$ before and after incubation with CTL. Aliquots of Map mixed in five ratios, $100 \%$ live, $75 \%$ live/25\% killed, 50\% live/50\% killed, $25 \%$ live/75\% killed, and $100 \%$ killed, were prepared to obtain $2 \times 10^{7}$ total Map in each aliquot, added to the cultures of MoMФ at a MOI of 10 , and incubated for $3 \mathrm{~h}$ as described previously [6]. The cultures were then washed to remove free bacteria. Adherent cells were collected and transferred into new $15 \mathrm{~mL}$ tubes. $10^{7}$ fresh mdPBMC were added for each tube and all the cells were mixed followed by centrifugation. The cell pellet in each tube was lysed with saponin as described above, and lysates stored at $-20{ }^{\circ} \mathrm{C}$ until use.

\subsubsection{PMA treatment, DNA extraction and $q P C R$}

Propidium monoazide (PMA) treatment of the cell lysates was carried out as previously described [6]. Briefly, $1 \mu \mathrm{L}$ of $20 \mathrm{mM}$ PMA working stock solution was added to $400 \mu \mathrm{L}$ of each previously prepared cell lysates to reach a final dye concentration of $50 \mu \mathrm{M}$. The translucent PMA-treated tubes were incubated at room temperature for five minutes in the dark on a rocker. The tubes were then placed in a plastic tray prepared with a frozen ice pack wrapped in aluminum foil. The tray was then placed on a rocking platform to ensure continuous mixing during light exposure. Light exposure was performed for five minutes using a halogen lamp with a $650 \mathrm{~W}$ bulb placed at a distance of $\sim 20 \mathrm{~cm}$ from the tubes. Cells were subsequently harvested by centrifugation at $10,000 \mathrm{~g}$ for five minutes. Supernatants were discarded, and the cell pellets processed for DNA isolation [19].

DNA extraction was performed according to the protocol for Gram-positive bacteria using DNeasy ${ }^{\circledR}$ Blood and Tissue kit (Qiagen, USA) following enzymatic lysis to facilitate breakdown of the Map cell wall as described by Park et al. [19]. TaqMan Quantitative Real-Time PCR, targeting the single copy F57 gene specific for Map (F57 qRT-PCR) was used to determine the activity of intracellular Map killing as described by Kralik et al. [20] and Abdellrazeq et al. [6]. The reaction was performed according to Schönenbrücher et al. [21] using a StepOnePlus Real-Time PCR machine (Applied Biosystems, CA). Map gDNA prepared from pure culture was used to generate a standard curve with the F57 probe, made with 8 dilutions starting with $4 \times 10^{7}$ copies down to 4 copies. The sequences of the primers and probes were the same as previously described [19]. The total reaction volume was $25 \mu \mathrm{L}$ including $5 \mu \mathrm{L}$ of the DNA sample, and reactions were run for 40 cycles. The mean values of the cycle threshold $\left(C_{T}\right)$ were analyzed using StepOne Software v2.1 (Applied Biosystems, CA).

\subsection{MHC blocking}

Four identical sets of unseparated mdPBMC cultures were prepared for the comparative study. One set was used as a control with no antibody added. One set was incubated with both MHC I and MHC II $(0.5 \mu \mathrm{g} / \mathrm{ml})$ and one each with either antibody to MHC I or MHC II. In addition, one culture was prepared and cultured with an isotype control antibody to verify mAbs specific for other antigens have no effect on the proliferative response to MMP (Table 1). Cultures were subjected to two rounds of stimulation with MMP as described above, and cell activation and proliferation assessed using FC. The resultant cultures of cells were then incubated with infected MoMФ for $24 \mathrm{~h}$. The cells were collected and processed to determine the CTL activity in each preparation of cells using the bacterium viability assay as described.

\subsection{Flow cytometric analysis}

After the second round of antigen stimulation, cells were washed once in PBS/ACD, centrifuged, re-suspended in serumfree RPMI and counted. For antibody labeling, cells were distributed into 96-well polystyrene V-bottom microplates $\left(10^{6}\right.$ cells/well). Combinations of mAbs (Table 1) obtained from the WSU Monoclonal Antibody Center (WSUMAC) were used for labeling as previously described [22]. Data were collected on a modified FACS Calibur DxP8 Analyzer equipped with a FlowJo operating system (Cytek Biosciences Inc. Fremont, CA) and analyzed with FCS Express software (DeNovo Software, Glendale, CA) [17]. The gating strategy used to collect the data is shown in Fig. 2. Side scatter (SSC) and forward scatter (FSC) were used to identify small and large lymphocytes. FSC-Height vs FSC-Width (FSC-H vs FSC-W) was used to exclude doublets. Selective electronic gating was used to isolate CD4 and CD8 T cells for determination of their activation status.

\subsection{Statistical methods}

Data were imported into SAS software (SAS for Windows, version 9.3) for statistical analysis and graphical presentation. The data were analyzed using a mixed modeling procedure (PROC GLIMMIX). For proportional response data (proportion activated $T$ cells), statistical models included the main fixed effects of MMP stimulation (MMP, diluent control) and T cell type (CD4, CD8), the interaction term of these effects, and was based on the binomial response distribution and Kenward-Roger degrees of freedom approximation. These experiments were considered to be of heirarchical design; the corresponding statistical models thus included random residuals defined by $\mathrm{T}$ cell types nested within each subject (blood donor steer), and an unstructured (Cholesky)

Table 1

Monoclonal antibodies used in the present study.

\begin{tabular}{lll}
\hline mAb & Isotype & Specificity \\
\hline CAM36A & IgG1 & CD14 \\
CAM66A & IgM & CD14 \\
209MD26A & IgG2a & CD209 \\
ILA11A & IgG2a & CD4 \\
CACT138A & IgG1 & CD4 \\
7C2B & IgG2a & CD8 \\
CACT80C & IgG1 & CD8 \\
ILA116A & IgG3 & CD45R0 \\
H58A & IgG2a & MHC I \\
PT85A & IgG2a & MHC I \\
TH14B & IgG2a & MHC II BoLA DR \\
TH81A5 & IgG2a & MHC II BoLA DQ \\
CAT82A & IgG1 & MHC II \\
\hline
\end{tabular}




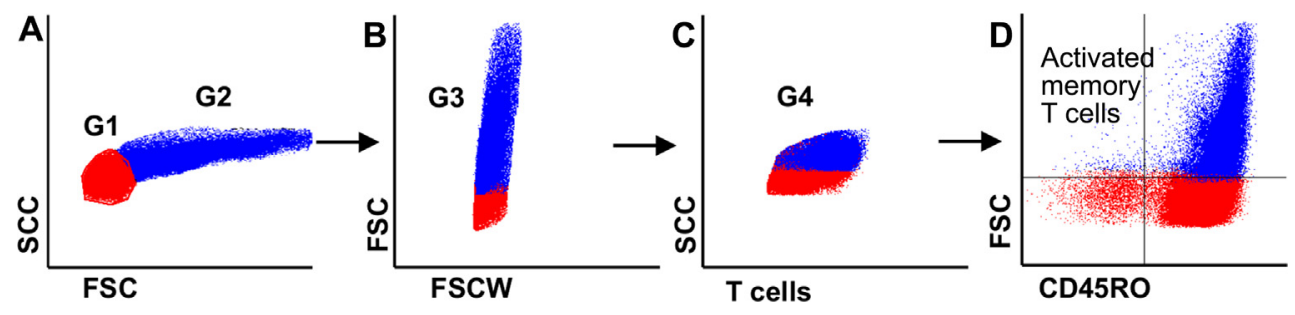

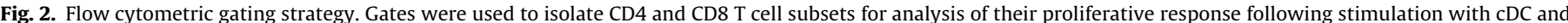

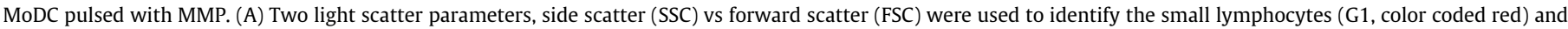

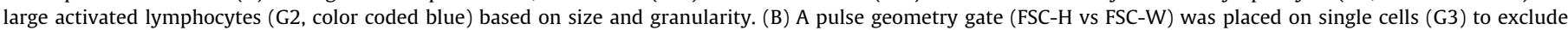

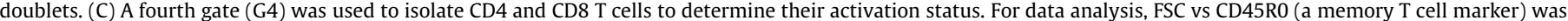

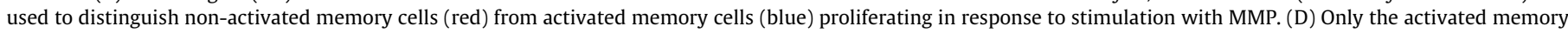

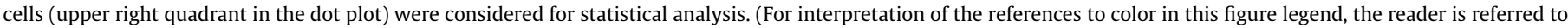
the web version of this article.)

covariance matrix. Multiple comparisons were adjusted using the method of Holm-Tukey (overall $\alpha=0.05$ ).

For $\mathrm{C}_{\mathrm{T}}$ response data (qPCR estimation of intracellular Map killing), statistical models included the single main fixed effect of manipulating the mdPBMC context of MMP stimulation (manipulation of T cell context or manipulation of MHC I and II context, each with controls). These analyses were based on the Poisson response distribution and Kenward-Roger degrees of freedom approximation, and included a random effect of residuals defined by subjects and using the default variance component structure of the covariance matrix. Under these experimental scenarios, only comparisons of interest were made utilizing the Dunnett method of adjustment for multiple comparisons (overall $\alpha=0.05$ ).

\section{Results}

3.1. The proliferative response of $\mathrm{IDPBMC}$ is reduced if either $C D 4$ or CD8 $T$ cells are depleted before stimulation with MMP

The experiments were conducted to verify and gain further insight into the effect of CD4 and CD8 depletion on CTL development following MMP stimulation. Negative selection was used to deplete either CD4 or CD8 T cells from mdPBMC. The depletion strategy included use of a mAb to the $\delta$ chain of the $\gamma \delta$ TCR to exclude any potential effect of $\gamma \delta$ T cells on the proliferative response to MMP. Previous studies established that NK cells do not contribute to the proliferative response to MMP [6]. Little difference could be detected between the untreated positive control preparation of mdPBMC and preparations depleted of either CD4 or CD8 T cells after one round of stimulation with MMP (not shown). However, clear differences were evident after two rounds of stimulation (Fig. 3).

mdPBMC incubated with MMP had significantly larger $\left(F_{\mathrm{MMP}}=168.06, P=0.0002\right)$ proportions of activated CD4 T cells $\left(P_{a d j}=0.0005\right)$ and activated $\mathrm{CD}^{+} \mathrm{T}$ cells $\left(P_{a d j}=0.0013\right)$ than mdPBMC incubated without MMP. Significant differences were not detected between the proportions of activated CD4 and CD8 $\mathrm{T}$ cells within the mdPBMC $\left(F_{\mathrm{CD}}=0.7277, P=0.7277\right)$ nor in the change induced by MMP $\left(F_{\mathrm{MMP}^{*} \mathrm{CD}}=2.61, P=0.1816\right)$.

The cellular context during incubation with MMP did have a significant effect on the proportions of activated T cells ( $F_{\text {Con- }}$ text $=44.68, P=0.0053)$. Post-hoc comparisons were limited to within each cell type since the effects on the two phenotypes of $\mathrm{T}$ cells were parallel (see Fig. 3 ) and only marginally different in magnitude $\left(F_{\text {Context }}{ }^{\mathrm{C} D}=13.23, P=0.0308\right)$. The proportion of activated CD4 T cells in mdPBMC depleted of both CD8 T cells and $\gamma \delta \mathrm{T}$ cells was significantly less than the proportions present in whole mdPBMC $\left(P_{a d j}=0.0327\right)$ and mdPBMC depleted of only $\gamma \delta$ T cells $\left(P_{a d j}=0.0225\right)$. The proportion of activated CD4 T cells in mdPBMC depleted of $\gamma \delta$ T cells was not significantly different than that in whole $\operatorname{mdPBMC}\left(P_{a d j}=0.0542\right)$.

Similarly, the proportion of activated CD8 T cells in mdPBMC depleted of both CD4 T cells and $\gamma \delta$ T cells was significantly less than the proportions within whole $\operatorname{mdPBMC}\left(P_{a d j}=0.0131\right)$ and mdPBMC depleted of only $\gamma \delta$ T cells $\left(P_{a d j}=0.0022\right)$. The proportion of activated CD8 T cells in mdPBMC depleted of only $\gamma \delta$ T-cells was not significantly different than that in whole mdPBMC $\left(P_{a d j}=0.0786\right)$.

\subsection{The CTL activity of $M A P B M C$ is reduced if either CD4 or CD8 T cells are depleted before stimulation with MMP}

In conjunction with experiments to investigate the effects of Tcell depletion on the proliferative response to MMP, one set of cell preparations was used to determine the effects of depletion on CTL activity against intracellular Map in target MoMФ (Fig. 4). Manipulation of cellular context did significantly affect killing of intracellular bacteria (as estimated by $C_{\mathrm{T}} ; F=16.40, P<0.0001$ ). Fig. 4 depicts the outcomes of this experiment relative to a standardized scale of intracellular killing whereas statistical comparisons to the maximal killing produced by whole mdPBMC 24-hours post stimulation with MMP are shown in Fig. 5. The intracellular killing of Map in MoMФ co-cultured with MMP-stimulated whole mdPBMC was significantly greater than the control conditions (vs. MoMФ at 0-hours and at 24-hours post-stimulation, each $P_{a d j}<0.0001$; vs. MoMФ -control at 24-hours post-stimulation, $\left.P_{a d j}=0.0005\right)$. A significant reduction in intracellular killing of Map was not detected when only $\gamma \delta$ T-cells were depleted from mdPBMC prior to MMP stimulation $\left(P_{a d j}=0.4682\right)$, but was detected with the additional depletion of CD4 T cells $\left(P_{a d j}=0.0457\right)$ or CD8 T cells $\left(P_{a d j}=0.0089\right)$.

\subsection{Development of CD8 CTL to Map is inhibited by mAb blockade of MHC class I and/or class II molecules}

Depletion experiments confirmed the requirement of both CD4 and CD8 T cells during priming by DC for the generation of significant anti-Map CTL activity ex vivo. However, depletion experiments did not reveal whether development of CTL activity required cognate recognition of MMP epitopes presented on APC MHC I and MHC II molecules by CD4 and CD8 T cells during antigenic stimulation. Our previous studies of the recall response to Map/ $\Delta$ relA and MMP revealed the recall response was blocked in the presence of mAbs to both MHC I and MHC II molecules [11], but the effect of individual MHC class I or class II molecule blockade was not investigated. To complete the last set of experiments in this study, mdPBMC were stimulated with MMP in the presence of mAbs specific for either or both MHC I and MHC II molecules (Table 1). To maintain consistency with the initial studies, two 

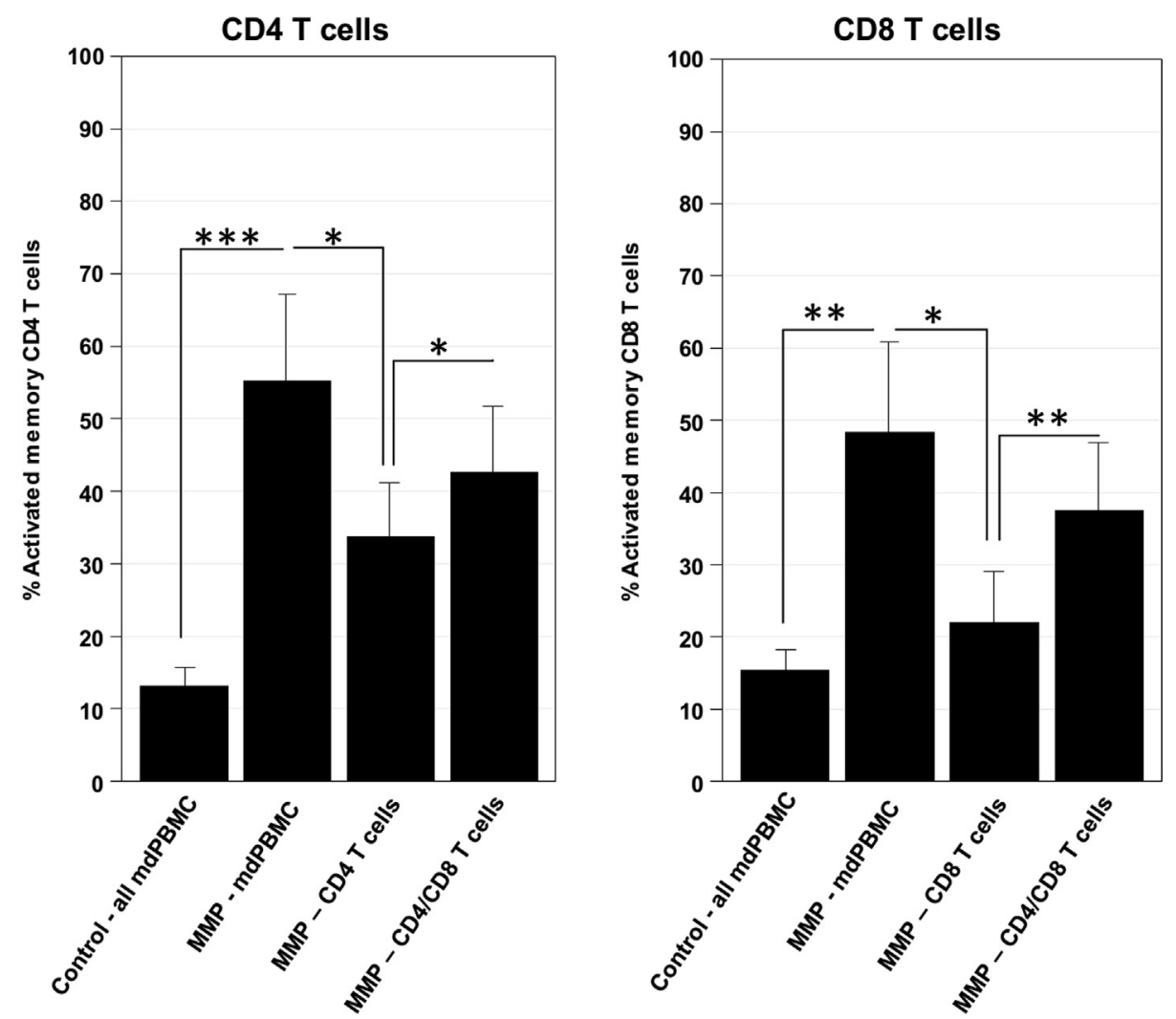

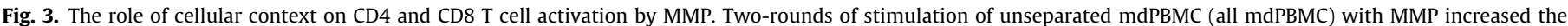

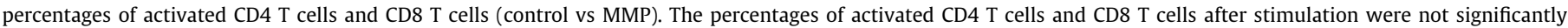

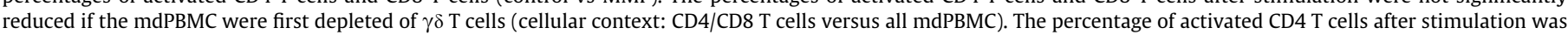

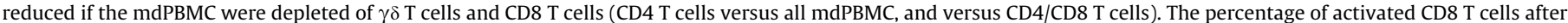

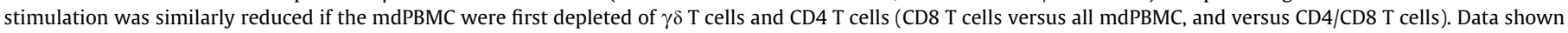

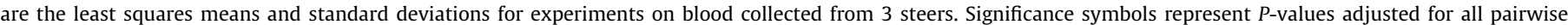
comparisons such that: ${ }^{*}, P_{a d j}<0.05 ;{ }^{* *}, P_{a d j}<0.01 ;{ }^{* * *}, P_{a d j}<0.001$.

mAbs were used for MHC I blockade and two mAbs (one specific for the bovine orthologue of HLA-DR, one specific for the bovine orthologue of HLA-DQ) were used for MHC II blockade. Comparison of the effect of an isotype control antibody, on the proliferative response to MMP with a culture of MdPBMC with no treatment, showed there was no nonspecific inhibitory effect on the proliferative response to MMP (Fig. 6A). However, the effect of MHC molecule blockade on cell proliferation and the development of CTL activity against intracellular Map was significant $(F=29.05$, $P<0.0001)$. The intracellular killing of Map by CTL in whole mdPBMC was significantly greater (all $P_{a d j}<0.0001$ ) than the negative control conditions and to that observed in cultures containing mAbs to either MHC I or MHC II molecules as well as in the presence of both MHC I and MHC II mAbs (Fig. 6B).

\section{Discussion}

Extensive studies have been conducted to elucidate the mechanisms regulating development of CD8 CTL activity against viral and bacterial pathogens, intracellular parasites, and cancers with the long-term objective of vaccine development. Cumulative studies have shown DC play a central role in stimulating CTL activity through cross presentation of antigenic epitopes presented in context of MHC I molecules (reviewed in $[23,24]$ ). What has not been fully explained in these studies is the role of CD4 T cells in the development of CD8 CTL activity. Indeed, reports on the role of CD4 T cell help seems to vary greatly between different model systems. Development of the primary CTL response to highly inflammatory targets, such as whole organism or bacterial membrane- based vaccines, are reported to be CD4 $\mathrm{T}$ cell independent $[25,26]$, while CD4 T cell help during priming are reported to be necessary for the development of a functional memory CTL response to these antigens [27-30]. CD4 T-cell help has also been reported to be necessary for activation of the CTL recall response. In contrast, the generation of both primary and recall CD8 CTL responses to poorly antigenic targets, including peptide immunogens and neoplastic cells, have been reported to require CD4 T cell help during priming and recall responses [31,32].

The mechanism of action of CD4 T cell help in these systems has not been clearly elucidated. Some studies have suggested CD4 T cells may play an indirect role and that interaction of CD154 (expressed on CD8 T cells) with CD40 (expressed on APC) might be the triggering event that initiates the primary activation and secondary expansion of CD8 T cells (reviewed in [33-35]). Results from other studies have suggested that cognate recognition of antigens presented in the context of DC MHC class II and class I molecules, coupled with subsequent stimulation by DC through ancillary receptor-ligand interactions, are key steps in priming CTL responses [36,37]. Although complex inbred mouse models have provided insight into the events associated with the generation of CTL in vivo, additional information is still needed to fully detail the events regulating development of CTL responses in outbred species, like cattle and humans. The present studies were conducted using an outbred bovine model system to characterize the CTL response to a candidate Map peptide-based vaccine.

Key to the development of our model system was the finding that CD209 is uniquely expressed on CDC in blood and MoDC in cattle [11]. Due to the size of cattle, access to large volumes of 


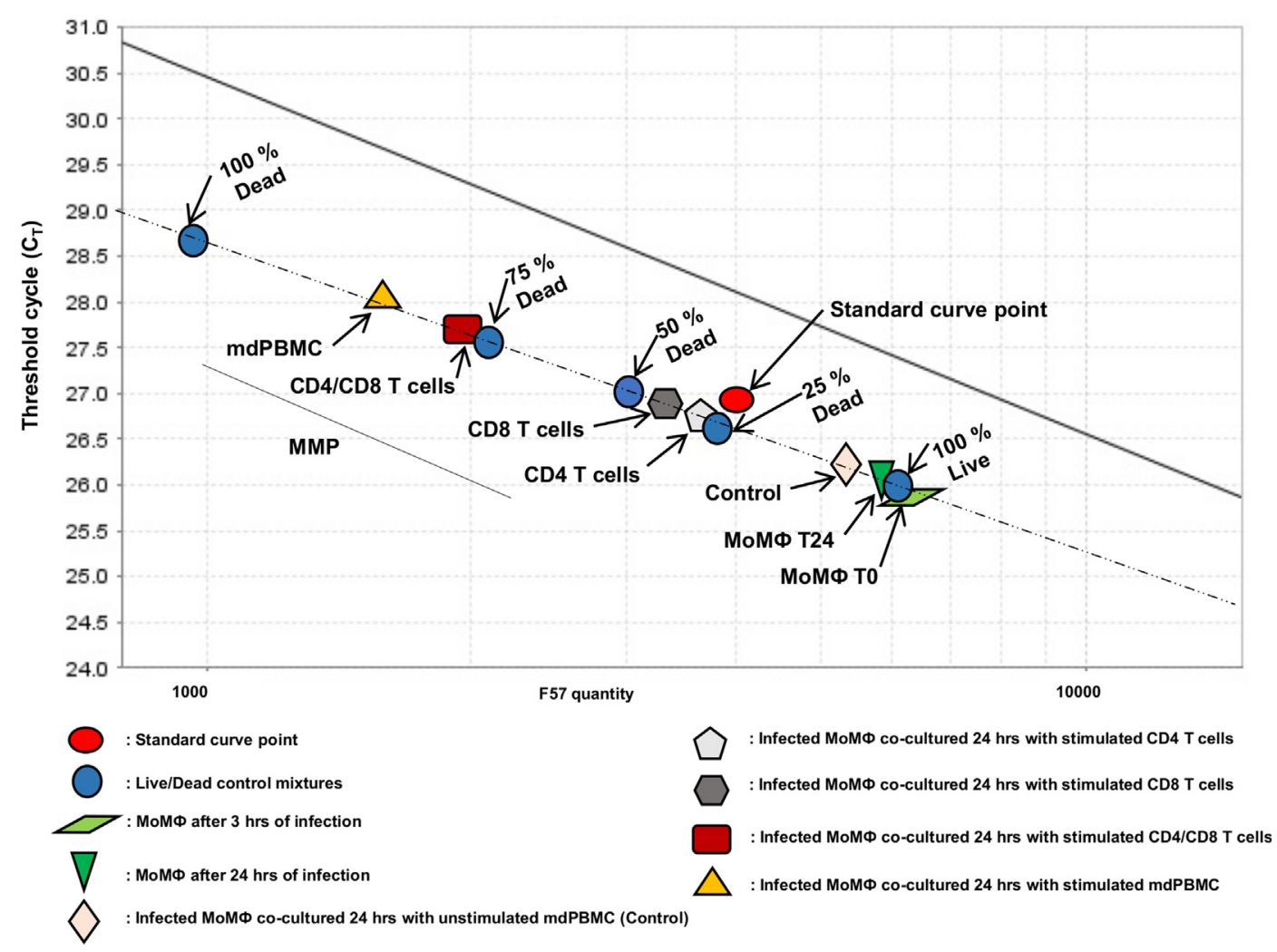

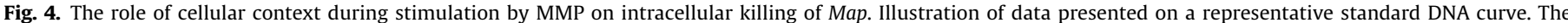

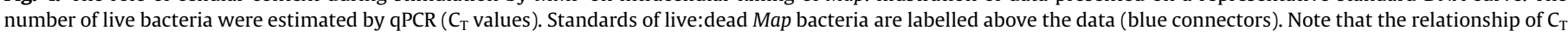

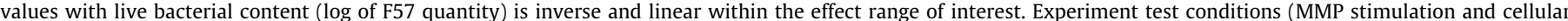

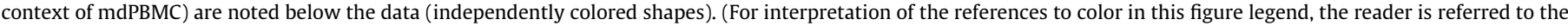
web version of this article.)

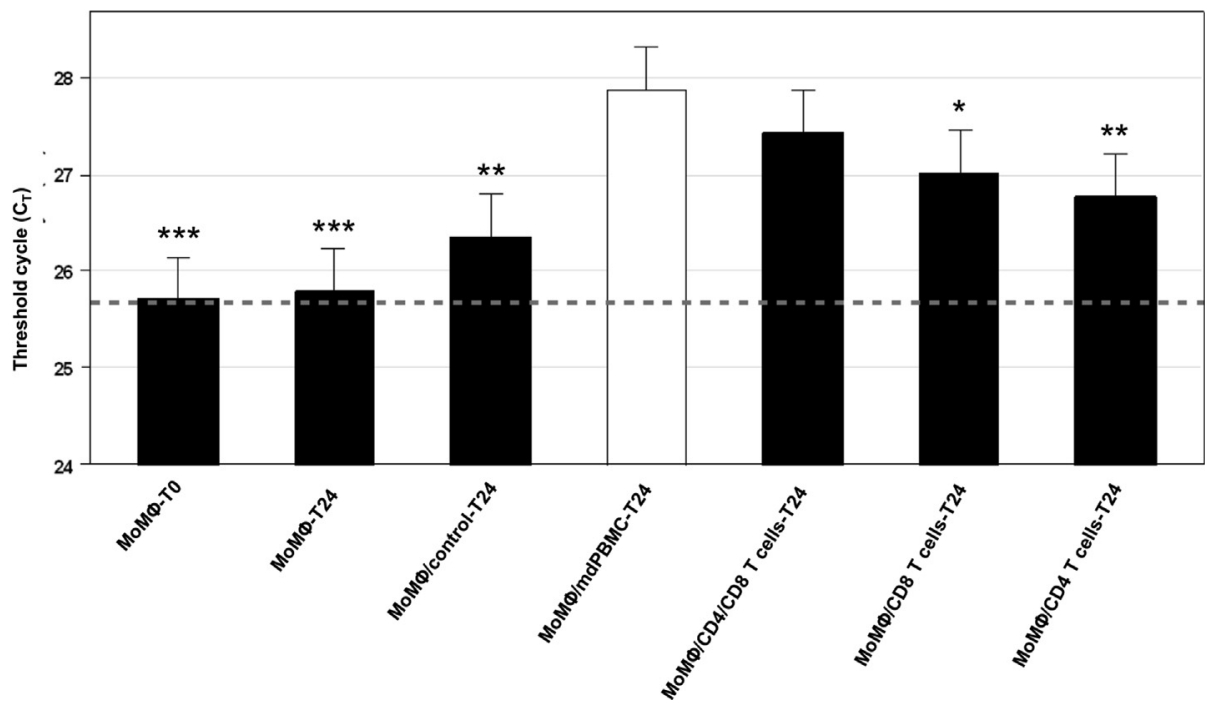

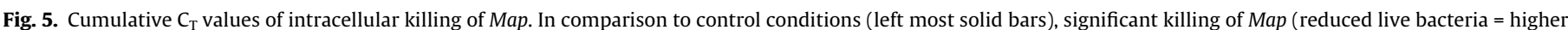

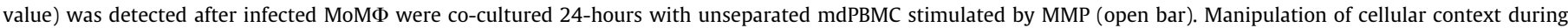

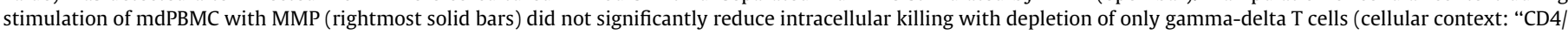

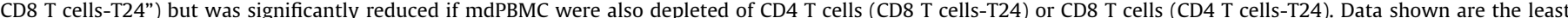

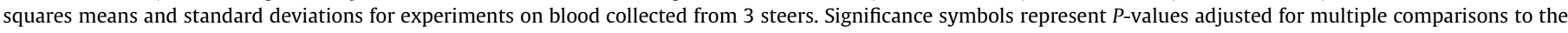
condition of maximum killing activity (open bar) such that: ${ }^{*}, P_{a d j}<0.05 ;{ }^{* *}, P_{a d j}<0.01{ }^{* * *}, P_{a d j}<0.001$.

blood obviated the difficulty in obtaining sufficient quantities of cDC for comparative studies with MoDC [11]. The development of a bovine DC-lymphocyte culture system enabled dissection of primary and recall CTL immune responses to antigenic peptides presented in context of MHC I and MHC II molecules under defined conditions. The Map/ $\Delta$ relA major membrane protein antigen, MMP, provided a model peptide antigen to study factors affecting development of CTL to a candidate peptide vaccine. Finally, development 
A

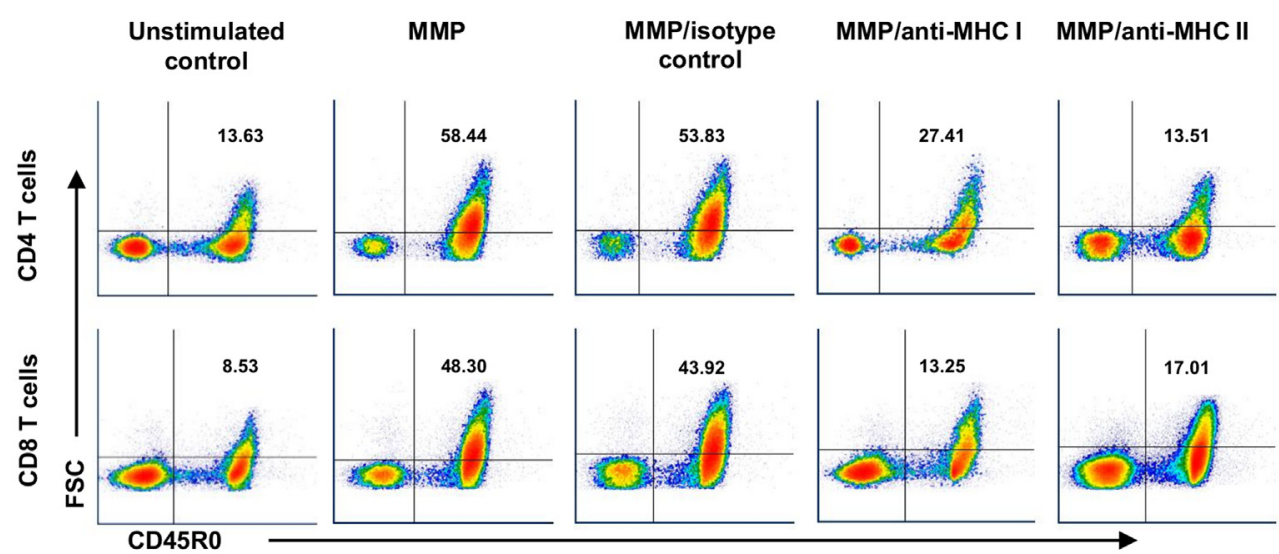

B

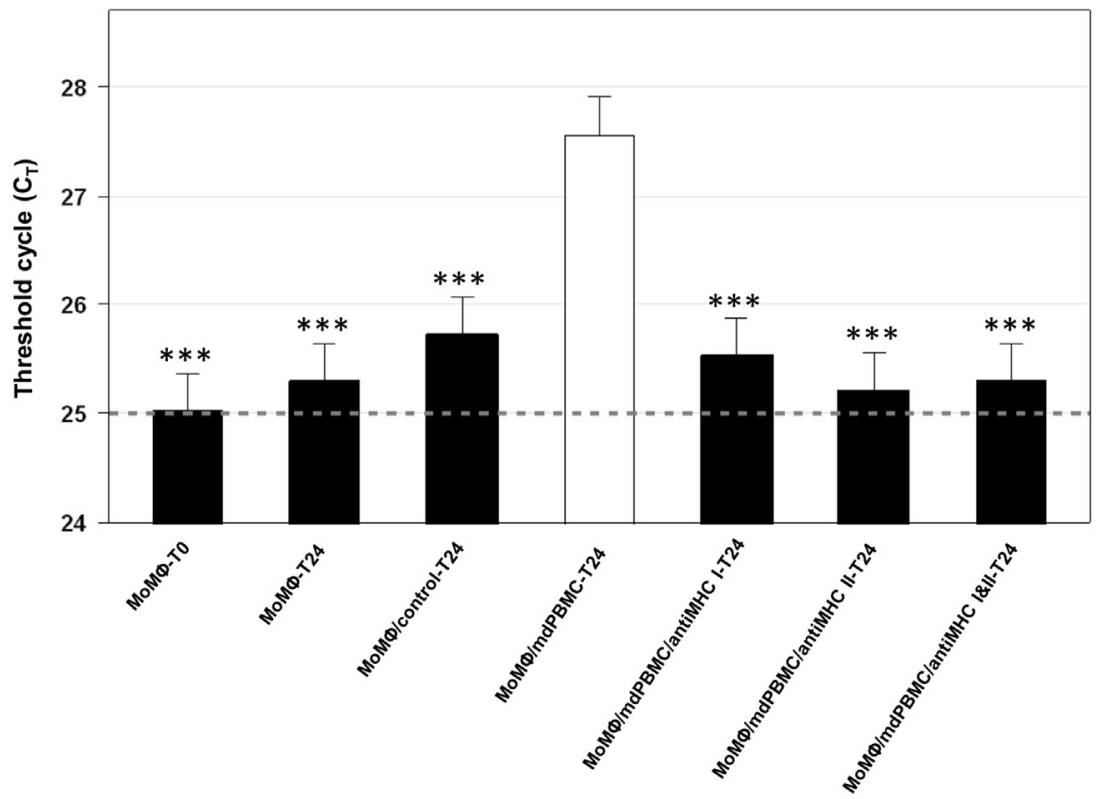

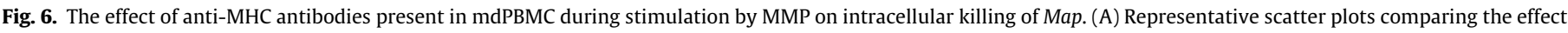

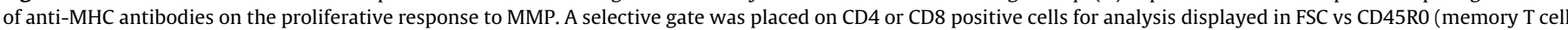

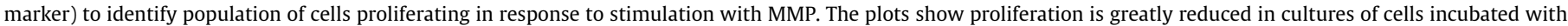

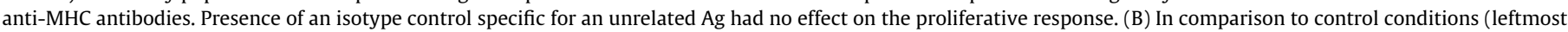

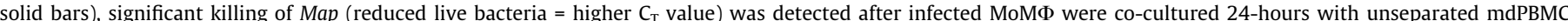

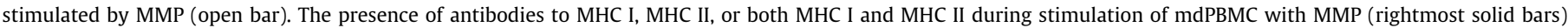

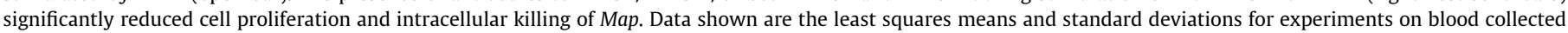

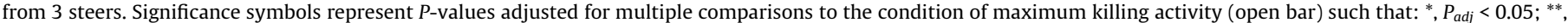
$P_{a d j}<0.01 ; * * *, P_{a d j}<0.001$.

of a bacterium viability assay provided a way to study the mechanisms used for the intracellular killing of Map in infected target cells [6]. The development of an assay overcame one of the difficulties of studying the immune response to slow growing mycobacterial pathogens. Slow growing bacteria like Map, take six or more weeks before colonies begin to be detectable when using the colony forming unit assay as a readout to analyze the effector $\mathrm{T}$ cell response that occurs following antigenic stimulation.

Using a Map/ArelA-vaccinated steer, we first used our model system to dissect the ex vivo recall response to Map/ArelA and MMP. The studies demonstrated that the main cell subsets proliferating in response to stimulation with Map/ArelA or MMPpulsed DC were CD4 and CD8 T cells. The responses were MHCrestricted. Killing activity was mediated primarily by CD8 T cells through the perforin-granzyme B pathway [6]. A preliminary CD4 $\mathrm{T}$ cell depletion study indicated development of CTL activity was reduced if $\mathrm{CD} 4 \mathrm{~T}$ cells were removed from cultures before stimula- tion with Ag-pulsed DC [6]. The data provided support for the supposition that CD4 $\mathrm{T}$ cell help is essential for initiation of a functional CD8 T cell recall response to Map/ArelA and MMP.

Since CD4 T cell help during priming is often observed for the generation of a primary CTL response to non-inflammatory targets in mice, we conducted the present ex vivo study to determine if this observation was the same in regard to the Map/ArelA and MMP candidate vaccines. In this study, we found the primary CD8 CTL responses were significantly diminished in cultures depleted of CD4 T cells prior to antigenic stimulation by DC. We also found that CD8 CTL responses were blocked in whole mdPBMC cultures in the presence of mAbs specific for MHC class I and MHC class II molecules. Importantly, we observed there was complete blockade of CD4 and CD8 T cell activation in the presence of mAbs to either MHC I or MHC II alone. The data presented here provide evidence that simultaneous cognate CD8 and CD4 T cell recognition of antigenic peptides presented on MHC I and MHC II mole- 
cules is essential for development of a functional primary CTL response to MMP.

The importance of CD4 and CD8 T cell cognate antigen recognition to the development of a functional primary CTL response to a bovine pathogen was previously demonstrated in one other study using an ex vivo Theileria parva culture system [38]. In this study, $T$. parva-infected lymphocytes, which express MHC class I and class II molecules, were used as APC, and were cultured in the presence of T. parva-naïve CD8 T cells, with or without primed CD4 T cells. $T$. parva-specific CD8 CTL developed only in cultures that contained primed CD4 T cells. Furthermore, if the primed CD4 T cells were cultured in the same plate, but separated from the APC and CD8 $\mathrm{T}$ cells by a semi-permeable membrane, no primary CD8 CTL response to $T$. parva developed, indicating that direct cell-cell contact between APC, CD4 T cells, and CD8 T cells is required for the development of a primary CTL response in this system. This study, like the present study, provides evidence of the importance of simultaneous cognate antigen recognition by CD4 and CD8 T cells for the development of a functional CTL response in the cattle.

In summary, analysis of the immune response to a Map/relA deletion mutant and a candidate peptide-based vaccine for Map in cattle have provided insight into factors regulating the development of CTL to an intracellular pathogen that are of universal importance. Deletion of relA disrupted the pathways used by Map to dysregulate the immune response and allowed for the development of an immune response that cleared the infection with the mutant. Analysis of the recall response revealed vaccination led to development of a CD8 CTL response that targeted a membrane protein, MMP. Analysis of the entire immune response to MMP ex vivo revealed simultaneous cognate recognition of antigenic peptides by CD4 and CD8 T cells, presented by DC pulsed with MMP is essential for generation of CTL against Map. Blocking of $\mathrm{Ag}$ presentation by mAbs to either MHC I or MHC II molecules blocked the proliferative and CTL responses to Map. The findings may have revealed an elusive component of the CTL response to pathogens. The ex vivo platform developed to conduct the studies provide an opportunity for further in depth studies in large outbred animal species like cattle and also humans.

\section{Authors contribution}

GSA and WCD conceived the study. GSA and WCD participated in the design of the protocol to conduct the studies. JPB participated in the development and use of the Map major membrane protein (MMP). GSA conducted the experiments. MME, AHM and VH participated in the conduct of the experiments. GSA and DAS participated in statistical analysis of the data. GSA, LMF, MME, AHM, KTP, WCD, JPB, DAS, and WMC participated in the writing and interpretation of the results. WCD and JPB obtained the funding for the project. WCD oversaw and participated in all aspects of the study. All authors read and approved the final manuscript.

\section{Declaration of Competing Interest}

The authors declare that they have no known competing financial interests or personal relationships that could have appeared to influence the work reported in this paper.

\section{Acknowledgements}

The authors wish to acknowledge the excellent technical support and animal care provided by Emma Karol and her staff. The results of this study were presented orally in 2018 Berkeley conference (Mycobacterial Implications in Crohn's and Chronic Inflammatory Diseases), Lawrence Hall of Science | Berkeley, CA, USA.

\section{Funding}

Support was provided by the Wash. State Univ. Monoclonal Antibody Center.

\section{References}

[1] Singh SV, Kumar N, Sohal JS, Singh AV, Singh PK, Agrawal ND, et al. First mass screening of the human population to estimate the bio-load of Mycobacterium avium sub-species paratuberculosis in North India. JPHE 2014;6:20-9.

[2] Naser SA, Sagramsingh SR, Naser AS, Thanigachalam S. Mycobacterium avium subspecies paratuberculosis causes Crohn's disease in some inflammatory bowel disease patients. World J Gastroenterol 2014;20:7403-15.

[3] Johne HA, Frothingham L. Ein eigenthumlicher fall von tuberculosis beim rind [A peculiar case of tuberculosis in a cow]. Deutsche Zeitschr Tierm Path 1895;21(438-454):438-54.

[4] Davis WC, Kuenstner JT, Singh SV. Resolution of Crohn's (Johne's) disease with antibiotics: what are the next steps?. Expert Rev Gastroenterol Hepatol 2017:1-4.

[5] Singh SV, Kuenstner JT, Davis WC, Agarwal P, Kumar N, Singh D, et al. Concurrent resolution of chronic diarrhea likely due to crohn's disease and infection with Mycobacterium avium paratuberculosis. Front Med (Lausanne) 2016;3:49.

[6] Abdellrazeq GS, Elnaggar MM, Bannantine JP, Park KT, Souza CD, Backer B, et al. A Mycobacterium avium subsp. paratuberculosis relA deletion mutant and a $35 \mathrm{kDa}$ major membrane protein elicit development of cytotoxic T lymphocytes with ability to kill intracellular bacteria. Vet Res 2018;49:53.

[7] Abdellrazeq GS, Elnaggar MM, Bannantine JP, Schneider DA, Souza CD, Hwang J, et al. A peptide-based vaccine for Mycobacterium avium subspecies paratuberculosis. Vaccine 2019;37:2783-90.

[8] Walburger A, Koul A, Ferrari G, Nguyen L, Prescianotto-Baschong C, Huygen K, et al. Protein kinase $\mathrm{G}$ from pathogenic mycobacteria promotes survival within macrophages. Science 2004;304:1800-4.

[9] Dahl JL, Kraus CN, Boshoff HIM, Doan B, Foley K, Avarbock D, et al. The role of RelMtb-mediated adaptation to stationary phase in long-term persistence of Mycobacterium tuberculosis in mice. Proc Natl Acad Sci USA 2003;100:10026-31.

[10] Park KT, Allen AJ, Bannantine JP, Seo KS, Hamilton MJ, Abdellrazeq GS, et al. Evaluation of two mutants of Mycobacterium avium subsp. paratuberculosis as candidates for a live attenuated vaccine for Johne's disease. Vaccine 2011;29:4709-19.

[11] Park KT, ElNaggar MM, Abdellrazeq GS, Bannantine JP, Mack V, Fry LM, et al Phenotype and function of CD209+ bovine blood dendritic cells, monocytederived-dendritic cells and monocyte-derived macrophages. PLoS ONE 2016;11:e0165247.

[12] Leite FL, Reinhardt TA, Bannantine JP, Stabel JR. Envelope protein complexes of Mycobacterium avium subsp. paratuberculosis and their antigenicity. Vet Microbiol 2015;175:275-85.

[13] Li L, Bannantine JP, Zhang Q, Amonsin A, May BJ, Alt D, et al. The complete genome sequence of Mycobacterium avium subspecies paratuberculosis. Proc Natl Acad Sci U S A 2005;102:12344-9.

[14] Planesse C, Nativel B, Iwema T, Gasque P, Robert-Da Silva C, Viranaicken W. Recombinant human HSP60 produced in ClearColi BL21(DE3) does not activate the NFkappaB pathway. Cytokine 2015;73:190-5.

[15] Park KT, Dahl JL, Bannantine JP, Barletta RG, Ahn J, Allen AJ, et al. Demonstration of allelic exchange in the slow-growing bacterium Mycobacterium avium subsp. paratuberculosis, and generation of mutants with deletions at the pknG, relA, and lsr2 loci. Appl Environ Microbiol 2008;74:1687-95.

[16] Park KT, Burnett S, Davis WC. Development and characterization of a monoclonal antibody specific for bovine CD209. Vet Immunol Immunopathol 2015;163:216-20.

[17] Park KT, Seo KS, Godwin NA, Van Wie BJ, Gulbahar MY, Park YH, et al Characterization and expression of monoclonal antibody-defined molecules on resting and activated bovine alphabeta, gammadelta T and NK cells. Vet Immunol Immunopathol 2015;168:118-30.

[18] Elnaggar MM, Abdellrazeq GS, Mack V, Fry LM, Davis WC, Park KT Characterization and use of new monoclonal antibodies to CD11c, CD14, and CD163 to analyze the phenotypic complexity of ruminant monocyte subsets. Vet Immunol Immunopathol 2016;178:57-63.

[19] Park KT, Allen AJ, Davis WC. Development of a novel DNA extraction method for identification and quantification of Mycobacterium avium subsp. paratuberculosis from tissue samples by real-time PCR. J Microbiol Methods 2014;99:58-65.

[20] Kralik P, Nocker A, Pavlik I. Mycobacterium avium subsp. paratuberculosis viability determination using F57 quantitative PCR in combination with propidium monoazide treatment. Int J Food Microbiol 2010;141(Suppl 1): S80-6.

[21] Schonenbrucher H, Abdulmawjood A, Failing K, Bulte M. New triplex real-time PCR assay for detection of Mycobacterium avium subsp. paratuberculosis in bovine feces. Appl Environ Microbiol 2008;74(9):2751-8. https://doi.org/ 10.1128/AEM.02534-07.

[22] Allen AJ, Park KT, Barrington GM, Hamilton MJ, Davis WC. Development of a bovine ileal cannulation model to study the immune response and 
mechanisms of pathogenesis paratuberculosis. Clin Vaccine Immunol 2009; 16:453-63.

[23] Blander JM. Regulation of the cell biology of antigen cross-presentation. Annu Rev Immunol 2018;36:717-53.

[24] Cruz FM, Colbert JD, Merino E, Kriegsman BA, Rock KL. The biology and underlying mechanisms of cross-presentation of exogenous antigens on MHCI molecules. Annu Rev Immunol 2017;35:149-76.

[25] Rahemtulla A, Fung-Leung WP, Schilham MW, Kündig TM, Sambhara SR, Narendran A, et al. Normal development and function of $\mathrm{CD}^{+}$cells but markedly decreased helper cell activity in mice lacking CD4. Nature 1991;353:180-4.

[26] Bachmann MF, Zinkernagel RM, Oxenius A. Immune responses in the absence of costimulation: viruses know the trick. J Immunol 1998;161:5791-4.

[27] Bevan MJ. Helping the CD8(+) T-cell response. Nat Rev Immuno 2004;4:595-602.

[28] Janssen EM, Lemmens EE, Wolfe T, Christen U, von Herrath MG, Schoenberger SP. CD4+ T cells are required for secondary expansion and memory in CD8+ T lymphocytes. Nature 2003;421:852-6.

[29] Shedlock DJ, Shen H. Requirement for CD4 T cell help in generating functional CD8 T cell memory. Science 2003;300:337-9.

[30] Sun JC, Bevan MJ. Defective CD8 T cell memory following acute infection without CD4 T cell help. Science 2003;300:339-42.
[31] Bennett SRM, Carbone FR, Karamalis F, Flavell RA, Miller JFAP, Heath WR. Help for cytotoxic-T-cell responses is mediated by CD40 signalling. Nature 1998;393:478-80.

[32] Ridge JP, Di Rosa F, Matzinger P. A conditioned dendritic cell can be a temporal bridge between a CD4 ${ }^{+}$T-helper and a T-killer cell. Nature 1998:393:474-8.

[33] Theisen Derek, Murphy Kenneth. The role of cDC1s in vivo: CD8 T cell priming through cross-presentation. F1000Res 2017;6:98. https://doi.org/10.12688/ f1000research10.12688/f1000research.9997.1.

[34] Shugart JA, Bambina S, Alice AF, Montler R, Bahjat KS. A self-help program for memory CD8+ T cells: positive feedback via CD40-CD40L signaling as a critical determinant of secondary expansion. PLoS ONE 2013;8:e64878.

[35] Kim J, Gambhir V, Alatery A, Basta S. Delivery of exogenous antigens to induce cytotoxic CD8+ $\mathrm{T}$ lymphocyte responses. J Biomed Biotechnol 2010;2010:218752.

[36] Smith CM, Wilson NS, Waithman J, Villadangos JA, Carbone FR, Heath WR, et al. Cognate $\mathrm{CD}^{+} \mathrm{T}$ cell licensing of dendritic cells in $\mathrm{CD}^{+} \mathrm{T}$ cell immunity. Nat Immunol 2004;5:1143-8.

[37] Behrens G, Li M, Smith CM, Belz GT, Mintern J, Carbone FR, et al. Helper T cells, dendritic cells and CTL immunity. Immunol Cell Biol 2004;82:84-90.

[38] Taracha ELN, Awino E, McKeever DJ. Distinct CD4 ${ }^{+} \mathrm{T}$ cell helper requirements in Theileria parva-immune and -naive bovine CTL precursors. J Immunol 1997;159:4539-45. 